\title{
EFFECT OF AQUA AEROBICS ON SELECTED SOMATIC, PHYSIOLOGICAL AND AEROBIC CAPACITY PARAMETERS II POSTMENOPAUSAL WOMEN
}

\author{
Joanna Kantyka, ${ }^{A, B, E}$ Damian Herman, ${ }^{\mathrm{B}, \mathrm{D}}$ Robert Roczniok ${ }^{\mathrm{C}}$ \\ The Jerzy Kukuczka Academy of Physical Education, Katowice, Poland

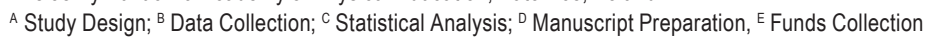 \\ Address for corpespondence: \\ Damian Herman \\ Akademia Wychowania Fizycznego im. J. Kukuczki w Katowicach \\ ul. Mikołowska 72, 40-065 Katowice, Poland \\ E-mail: d.herman@awf.katowice.pl
}

\begin{abstract}
Ahstract The world's population is aging. Aquatic exercises can improve the physical function in humans and raise the quality of their lives in middle and older age. The study aimed to determine the effect of aqua aerobics on the selected somatic, physiological and aerobic capacity parameters in postmenopausal women. 11 purposively selected women that were confirmed overweight or obese by $20 \%$ and had Body Mass Index of $30 \pm 5$ (the first stage of obesity) took part in aqua aerobics classes three times a week for 14 weeks. Their mean age was $56.18 \pm 3.19$ years and mean height was $166.5 \pm 7.41 \mathrm{~cm}$. The value of LBM and muscle mass $(p=0.04$ in both cases) were statistically significantly higher at study end compared with their baseline values, likewise haemoglobin concentration $(p=0.001)$, haematocrit $(p=0.03)$ and blood cell count $(p=0.01)$, whereas BMI $(p=0.02)$ and percentage body fat $(p=0.04)$ were significantly lower. The lactate analysis revealed significant changes in LA $\max (p=0.04)$, LAres9' $(p=0.02)$, Delta LAmax-LAsp $_{\text {L }}$ $(p=0.02)$ and Delta LAres9'-LAres3' $^{\prime}(p=0.0004)$. After 14 weeks of aqua aerobic workout, significant changes were noted in the selected somatic, morphological and aerobic capacity parameters in postmenopausal women, but the differences between the lipid profiles were insignificant.
\end{abstract}

KeV WOrlls body composition, lipid profile, blood count parameters, aerobic capacity, aqua aerobics, postmenopausal female

\section{Introduction}

According to international reports, the world's population of people aged 65 will double to 1 billion by 2030 raising the overall proportion of those aged 65 and older (National Institute on Aging..., 2007, pp. 6-7). At the same time, the number and proportion of the oldest-old (persons aged 80 years or over) is rising. By 2050 , this segment of the population is expected to reach 392 million or 4.1 per cent of the world population and by 2100 it would ascend to 830 million or 7.6 per cent of the population (UN, 2013).

Aging reduces and impairs tissue and organ function in the human body. Studies point out that the most common, negative effects of aging are the loss of skeletal muscle mass and strength (sarcopenia) (Adamo, Ferrar, 2006, pp. 310-331), bone density reduction and weakening bone structure (Humphries et al., 1999, pp. 364-374), 
and increasing body fat mass (Adams, O'Shea, O'Shea, 1999, pp. 65-77). The nervous system (Bellew, 2002, pp. 60-62) and metabolism have also been observed to function less efficiently as people age. These degenerative changes lead to various health and well-being problems affecting the everyday life of people. Researchers have established, however, that physical exercise can significantly contribute to the maintenance of the functional capacity in older persons (Hagberg et al., 1989; Hirvensalo, Rantanen, Heikkinen, 2000; Struck, Ross, 2006; Torlaković, Radjo, Dautbašić, Gec, 2010). According to the WHO guidelines of 2002, people should exercise at least 30 minutes a day. Interestingly, the physical activity standards are the same for people aged $65+$ and younger and healthy adults. As far as older people are concerned, the special role of strength training and exercises improving motor coordination, and thus reducing the risk of falling, are emphasised. Research has shown that resistance (strength) training can effectively sustain the well-being of elderly people (Roubenoff, 2007, pp. 208-212). However, gym exercises are frequently too straining on the body, so in the case of older persons all kinds of water exercises (aqua fat-burner, aqua step, aqua senior, aqua dance, aqua yoga) are recommended as particularly suitable. Exercising in water is safer than on land because the human body appears to lose $90 \%$ of its weight when immersed in water; with decreased load on the joints and the spine a greater range of motions is possible and the risk of injury to the locomotor system is reduced (Sheldahl, Buskirk, Loomis, Hodgson, Mendez, 1982, pp. 29-42). Further, because exercising in water (with or without accessories) involves greater energy output because the resistance of water must be overcome, aquatic exercises are more effective in increasing lean body mass and decreasing fat mass (Sonati, Modeneze, Vilarta, Maciel, Boccaletto, 2011, pp. 378-381) or BMI (Carrasco, Vaquero, 2012; Sonati et al., 2011) than if they were performed on land (Bergamin et al., 2013; Bocalini, Serra, Murad, Levy, 2008). Water resistance training is also reported to increase muscle mass and strength (Carrasco, Vaquero, 2012; Hansen, Allen, 2002; Raguso et al., 2006). In elderly persons doing aquatic training improves walking ability (Sato et al., 2011, pp. 331-335), balance and posture (Kaneda, Sato, Wakabayashi, Hanai, Nomura, 2008; Katsura et al., 2010; Simmons, Hansen, 1996) have been observed to improve. Rotstein, Harush, Vaisman (2008, pp. 352-359) have demonstrated that seven months of aquatic training improved bone mineral density (BMD) in post-menopausal women and Kamijo and Murakami (2009, pp. 55-62) have reported significantly lower blood triglyceride content in women that exercised in water for two years.

Research has provided interesting observations on people exercising in warm water and cold water. Regular exercises in thermal swimming pools and the use of rating of perceived exertion as a method of exercise monitoring have been found potentially useful tools for enhancing physical performance and body composition in healthy elderly (Bergamin et al., 2013). In the study by Sheldahl et al. (1982), cold water exercises (17-22 ${ }^{\circ} \mathrm{C}$ ) did not significantly change body weight, body fat, and fat-free body weight in seven obese women (fat mass $>30 \%$, a mean of $43 \%$ ) who exercised at moderate intensity (30-40\% of maximal oxygen uptake) five times per week for 90 minutes over a period of eight weeks. It is very probable, though, that in cold water people exercise at greater intensity to maintain thermal comfort.

There is also evidence that exercising in water can improve aerobic capacity. Bocalini et al. (2008) have reported that in a group of women aged $61+$ who exercised at $70 \% \mathrm{VO}_{2}$ max three times a week for 60 min over a period of 3 months maximal oxygen uptake increased by $42 \%$. The results of other authors (Broman, Quintana, Lindberg, Jansson, Kaijser, 2006; Takeshima et al., 2002) from studies with elderly women were also statistically significant. 
The conclusion that can be drawn from all these studies is that aquatic exercises can improve the physical function and raise the quality of human life (Devereux, Robertson, Briffa, 2005, pp. 102-108).

This study was undertaken to make up for insufficiency of information about morphological changes induced in humans by aquatic exercises and to determine the influence of 14 weeks of such exercises on the selected somatic, physiological and aerobic capacity parameters in postmenopausal women.

\section{Methods}

The study protocol was approved by the Bioethics Commission at the Jerzy Kukuczka Academy of Physical Education in Katowice by its decision no. 14 of 9 December 2008.

\section{Subjects}

The study was conducted with 11 purposively selected women that were confirmed overweight or obese by $20 \%$, and had the Body Mass Index of $30 \pm 5$ (the first stage of obesity). Their mean age was $56.18 \pm 3.19$ years and the mean height was $166.5 \pm 7.41 \mathrm{~cm}$.

All women screened for the study were examined by the attending physician to see if they could do exercises in water. Other inclusion criteria were the postmenopausal stage of the life cycle and age between 50 and 60 years. Seven women were excluded because they failed to meet the inclusion criteria.

\section{Procedures}

The selected women participated in 45-minute aqua-aerobic sessions that were held three times a week over a period of 3 months.

All exercises were performed in a swimming pool that was 60-160 cm deep, in a water temperature of $26-$ $28^{\circ} \mathrm{C}$. They were selected to match the participants' age and capabilities. Exercise intensity was controlled to remain between 128-137 heart rate per minute. Heart rate (HR) was constantly recorded during the sessions (the device was S810i, Polar Electro, Finland).

A single session consisted of three parts. It started with a 10-15 minute warm-up during which exercise intensity was around $128 \pm 5 \mathrm{HR} / \mathrm{min}$. The warm-up exercises mostly involved arm swings in different planes and directions and were done by the participants while jogging. An important objective of a warm-up for aqua aerobics is to rise the participants' body temperature so that the water they initially feel as cold be felt as warm.

The main part of a session lasted 25-30 minutes. Exercises were performed according to the principles of aqua aerobics at an intensity of ca. $132 \pm 5 \mathrm{HR} / \mathrm{min}$ (it was higher than during the warm-up). They were selected in such a way as to engage the whole body of the participants and involved the use of different accessories (aqua discs, noodles, swimming boards).

The third part lasted 5 minutes and included exercises the intensity of which was set to around $120 \mathrm{HR} / \mathrm{min}$. Participants exercised to slow music to allow them to stretch different muscle groups and relax psychologically and physiologically.

Participants exercised three times per week over a period of 14 weeks. A total of 42 sessions were held, with participants attending an average of 40 sessions. None of them dropped out before the end of the study.

To find out how aquatic exercises influenced the participants' body composition and selected blood cell count parameters they were assessed at baseline (assessment 1) and after intervention (assessment 2). 
The participants' body composition was analysed using an eight-electrode Biospace InBody 220 body composition analyser utilising bioelectrical impedance. The analyser was operated by a trained person certified by MEDfitness, the sole distributor of the device in Poland. Participants were weighed in the morning between 9 and $10 \mathrm{am}$, two hours after breakfast and after they had used the toilet, in the ambient temperature of $21^{\circ} \mathrm{C}$. They did not exercise or take any drugs before they were weighed. The weighing procedure was conducted twice, one day before the study and one day after they ended.

The Intraclass Correlation for the body composition analysis varied from 0.88 to 0.99 . The following parameters were measured:

- body mass (BM),

- body height,

- body mass index (BMI),

- total body water (TBW),

- fat free mass (FFM),

- body fat mass (BFM),

- skeletal muscle mass (SMM),

- percentage body fat (PBF).

Before breakfast, resting blood samples were drawn from the participants' antecubital veins using Advia 2120 , Siemens, Germany, to determine haematological variables (haemoglobin concentration (HGB), haematocrit value (HCT), the number of erythrocytes (RBC) and the lipid profile (total cholesterol (TC), high-density lipoproteincholesterol (HDL-C), low-density lipoprotein-cholesterol (LDL-C), and triglycerides (TG)). The following blood morphotic elements were tested:

- white blood cells (WBC),

- red blood cells (RBC),

- haemoglobin (HGB),

- haematocrit (HCT).

The lipoprotein profile:

- cholesterol (Ch-T),

- cholesterol (HDL-C),

- cholesterol (LDL-C),

- triglycerides (TG).

Maximal oxygen uptake $\left(\mathrm{VO}_{2} \mathrm{max}\right)$ was measured in the participants during a ramp test. Exercise intensity was increased by $15 \mathrm{~W} / 1 \mathrm{~min}(0.25 \mathrm{~W} / 1$ sek). The ramp test was selected in order to prevent local fatigue that may arise in untrained persons doing a progressive exercise test.

The participants' nutritional intake was limited to 2,000 kcal over the length of the study. The main sources of energy were carbohydrates, fats and proteins, which accounted for $50-60 \%$, ca $25 \%$, and $15-20 \%$ of daily energy requirement, respectively.

\section{Statistical analysis}

Data were analysed statistically with the use of Statistica 10.0 (StatSoft). Basic descriptive statistics were calculated and all variables were tested for normal distribution. Differences between the values of the investigated 
variables obtained during assessments 1 and 2 were tested for significance using the T-test for dependent variables. The level of statistical significance was set to $p<0.05$.

\section{Results}

The analysis of results obtained during assessment 2 showed that the participants' LBM and muscle mass $(p=0.04$ in both cases) were statistically significantly higher compared with their baseline values, but BMI $(p=0.02)$ and percentage body fat $(p=0.04)$ were significantly lower.

Table 1. Somatic parameters

\begin{tabular}{lcccccc}
\hline \multirow{2}{*}{ Variable } & \multicolumn{2}{c}{ Assessment 1 } & \multicolumn{2}{c}{ Assessment 2 } & \multirow{2}{*}{ Difference } & $p$ \\
\cline { 2 - 5 } & mean & std. dev. & mean & std. dev. & & \\
\hline Body mass & 78.30 & 12.35 & 77.70 & 9.88 & 0.6 & 0.13 \\
TBW & 35.64 & 4.41 & 36.16 & 4.02 & -0.52 & 0.17 \\
FatFM & 48.49 & 6.01 & 49.81 & 5.25 & -1.32 & 0.04 \\
BodyFM & 29.93 & 6.28 & 28.85 & 5.75 & 1.08 & 0.14 \\
SMM & 26.55 & 3.52 & 28.23 & 4.07 & -0.83 & 0.04 \\
BMI & 29.05 & 3.48 & 28.62 & 3.30 & 0.43 & 0.02 \\
PBF & 37.78 & 4.66 & 36.28 & 4.09 & 1.50 & 0.04 \\
\hline
\end{tabular}

It was also found that exercises in water significantly increased haemoglobin concentration $(p=0.001)$, haematocrit $(p=0.03)$ and blood cell count $(p=0.01)$ in the participants.

Table 2. Morphological parameters

\begin{tabular}{lcccccc}
\hline \multirow{2}{*}{ Variable } & \multicolumn{2}{c}{ Assessment 1 } & \multicolumn{2}{c}{ Assessment 2 } & \multirow{2}{*}{ Difference } & $\mathrm{p}$ \\
\cline { 2 - 5 } & mean & std. dev. & mean & std. dev. & & \\
\hline Wbc & 5.77 & 1.19 & 6.01 & 1.39 & -0.24 & 0.52 \\
$\mathrm{Rbc}$ & 4.58 & 0.33 & 4.72 & 0.28 & -0.14 & 0.01 \\
$\mathrm{Hgb}$ & 13.60 & 0.57 & 14.28 & 0.46 & -0.68 & 0.001 \\
$\mathrm{Hct}$ & 40.13 & 1.19 & 41.20 & 1.01 & -1.07 & 0.03 \\
\hline
\end{tabular}

The analysis of the lipid profiles did not show the results of assessments 1 and 2 to be statistically significantly different.

Table 3. Lipid parameters

\begin{tabular}{lcccccc}
\hline \multirow{2}{*}{ Variable } & \multicolumn{2}{c}{ Test 1 } & \multicolumn{2}{c}{ Test 2 } & \multirow{2}{*}{ Difference } & $p$ \\
\cline { 2 - 5 } & mean & std. dev. & mean & std. dev. & & \\
\hline Cholesterol & 6.07 & 1.47 & 5.81 & 1.25 & 0.26 & 0.24 \\
CholHDL & 1.75 & 0.36 & 1.82 & 0.47 & -0.07 & 0.26 \\
CholLDL & 3.76 & 1.12 & 3.56 & 1.00 & 0.20 & 0.25 \\
Triglic & 1.18 & 0.48 & 1.02 & 0.39 & 0.16 & 0.10 \\
\hline
\end{tabular}


The only variable that the second ramp test showed to be significantly different (higher) than at baseline was $\mathrm{WR}_{\max }(\mathrm{p}=0.01) ; \mathrm{HR}_{\max }, \mathrm{VO}_{2}$ max and $\mathrm{VE}_{\max }$ did not change statistically significantly compared with their initial values. The lactate analysis revealed significant changes in $\operatorname{LA}_{\max }(p=0.04), \operatorname{LA}_{\text {res }} 9^{\prime}(p=0.02)$, Delta LAmax-LAsp $(p=0.02)$ and Delta LAres9' $^{\prime}$-Ares3' $(p=0.0004)$.

Table 4. $\mathrm{VO}_{2} \mathrm{max}$ - Ramp test $15 \mathrm{~W} / 1 \mathrm{~min}$

\begin{tabular}{|c|c|c|c|c|c|c|}
\hline \multirow{2}{*}{ Variables } & \multicolumn{2}{|c|}{ Test 1} & \multicolumn{2}{|c|}{ Test 2} & \multirow{2}{*}{ Difference } & \multirow{2}{*}{$p$} \\
\hline & mean & std. dev. & mean & std. dev. & & \\
\hline $\mathrm{HR}_{\max }$ & 156.55 & 20.32 & 159.00 & 19.19 & -2.45 & 0.25 \\
\hline$W R_{\max }$ & 154.18 & 14.34 & 160.27 & 14.87 & -6.09 & 0.01 \\
\hline $\mathrm{VO}_{\max }$ & 22.00 & 4.20 & 22.64 & 4.13 & -0.63 & 0.13 \\
\hline $\mathrm{VE}_{\max }$ & 65.55 & 14.59 & 67.12 & 11.99 & -1.57 & 0.37 \\
\hline $\mathrm{LA}_{\mathrm{sp}}$ & 1.50 & 0.24 & 1.25 & 0.24 & 0.25 & 0.06 \\
\hline $\mathrm{LA}_{\max }$ & 5.04 & 1.02 & 5.95 & 1.15 & -0.91 & 0.04 \\
\hline $\mathrm{LA}_{\text {res3 }}$ & 6.00 & 1.35 & 6.4 & 1.15 & -0.39 & 0.31 \\
\hline $\mathrm{LA}_{\text {res6' }}$ & 5.77 & 1.34 & 5.44 & 1.09 & 0.33 & 0.38 \\
\hline $\mathrm{LA}_{\text {res9، }}$ & 5.53 & 1.36 & 4.56 & 0.86 & 1.17 & 0.02 \\
\hline Delta $_{\text {LAmax-LAsp }}$ & 3.54 & 1.03 & 4.71 & 1.25 & -1.16 & 0.02 \\
\hline Delta ${ }_{\text {LAres9'-LAres3' }}$ & -0.53 & 0.40 & -1.17 & 0.52 & 1.36 & 0.0004 \\
\hline
\end{tabular}

\section{Discussion}

In sedentary people taking up regular physical activity, the exercise stimulus triggers adaptive changes in different organs and systems of the body, particularly in the muscular, cardiorespiratory, circulatory, and hormonal systems. In this study, 14 weeks of aerobic workout had a significant effect on the participants' somatic characteristics. Statistical analysis conducted after the intervention showed significant changes in body lean mass (increase; $p=0.04$ ), muscle mass (increase; $p=0.04$ ), BMI (decrease; $p=0.02$ ) and percentage body fat (decrease; $p=0.04$ ) compared with their baseline values. That water exercises can improve the body composition has been reported by many authors (Bergamin et al., 2013; Fernández-Lao et al., 2013; Kim, O'sullivan, 2013; Taunton et al., 1996; Takeshima et al., 2002). The results of this study are consistent with those obtained by Sonati et al. (2011), who has demonstrated that regular aquatic exercises decrease body fat mass and increase fat-free mass (FFM) in physically active women. In contrast, Speakment and Westerterp $(2010,826-834)$ failed to find a relationship between increased physical activity and higher FFM in elderly persons.

Bergamin et al. (2013) had a group of 59 healthy elderly exercise in geothermal spring water $\left(36^{\circ} \mathrm{C}\right)$ for 24 weeks in order to assess the effectiveness of such exercises in improving the general fitness and muscle mass of the study participants and to compare the results of exercises performed in water and on land. The sample was randomised into three groups: an aquatic group (AG), a land group (LG), and a control group (CG). The AG and $L G$ groups followed a 6-month, twice-weekly, multimodality exercise intervention. The AG group underwent a protocol in hot-spring water $\left(36^{\circ} \mathrm{C}\right)$, while the $L G$ group exercised in a land-based environment. The authors of the study established that in the AG group fat mass (FM) and forearm fat decreased by $4 \%(p<0.05)$ and $9.2 \%(p<0.05)$, respectively, and calf muscle density increased by $1.8 \%(p<0.05)$; no changes in FFM were 
noted, though. Carrasco, Vaquero (2012) obtained similar results in a study involving a group of 38 postmenopausal women randomised into an exercise group (EG; $n=21$ ) and a control group (CG; $n=17$ ) The EG group exercised in a shallow pool twice a week for 45 min over a period of 12 months. The results show that workout in a shallow pool had significant implications for total body weight of participants in the EG group because their BMI decreased by an average of $-2.75 \%(p \leq 0.05)$. The results provide strong evidence that people exercising in a shallow pool can reduce their BMI. Ruoti, Troup, Berger (1994, pp. 140-145) have reported different results from a study on the effect of non-swimming exercises on muscle endurance, body fat, and aerobic work capacity in an older adult population. After 12 weeks of training, the values of all variables except for body composition were significantly different $(p<0.05)$.

In this study, the typically aerobic exercises induced adaptive changes in the participants' circulatory systems because of statistically significant increases in the levels of haemoglobin $(p=0.001)$ and haematocrit $(p=0.03)$, and in blood cell count $(p=0.01)$. The increases should be attributed to adaptive responses to exercising over a long period and the rising volumes of blood plasma. Physical activity enhanced the function of circulatory systems in the participants, thus improving their whole body function. However, the literature lacks evidence that various forms of aerobics have effect on blood parameters in people who regularly participate in such activities.

The lipid profiles of the women participating in this study were not significantly different after intervention from those established at baseline. This contrasts with the results obtained by Kamijo and Murakami (2009), according to which regular physical workout significantly reduced the blood levels of triglycerides in elderly females. The results of the LeMura et al. $(2000,451-458)$ study were similar in that they implied that aerobic exercises could improve the lipid-lipoprotein profile, endurance and body build in women. LeMura has reported that 16 weeks of training significantly reduced blood concentration of triglycerides $(p<0.05)$ and significantly increased blood concentration of high density lipoproteins (HDL-C) in the exercise group.

The only variable that the second ramp test in this study showed to have changed statistically significantly (increased) was $\mathrm{WR}_{\max }(\mathrm{p}=0.01)$. The values of $\mathrm{Hu}_{\max }, \mathrm{VO}_{2} \max$ and $\mathrm{VE}_{\max }$ were not significantly different from those recorded at baseline. The lactate analysis revealed significant changes in $L A_{\max }(p=0.04), L A_{\text {res }} 9^{\prime}(p=0.02)$, Delta $_{\text {LAmax-LAsp }}(p=0.02)$ and Delta ${ }_{\text {LAres9'-LAres3' }}(p=0.0004)$ after intervention.

In the study by Broman et al. (2006), elderly women (aged $69 \pm 4$ years) did high-intensity interval exercises in deep water twice a week over a period of 8 weeks. The authors have noted a significant decrease in the participants' heart rate during submaximal exercises (by $3 \%$ ), as well as increased maximal oxygen uptake and maximal ventilation levels $(p<0.01)$. Bocalini et al. (2008) have reported that because of 12 weeks of workout maximal oxygen uptake increased in the intervention group (women aged 62-75 years who exercised 60 minutes 3 times per week) by $42 \%$.

In the study by Tsourlou, Benik, Zafeiridis, Kellis, (2006, pp. 811-19) a significant improvement in the maximal isometric torque of knee extensors (10.5\%) and knee flexors (13.4\%) was noted in women aged 60+ who exercised in shallow water (three 60-minute sessions per week over a period of 24 weeks). Poyatos and Abellán (2011, pp. 17-30) have reported that resistance exercises performed by postmenopausal women (aged $55.4 \pm 6.5$ years) in shallow water for 45 minutes twice a week significantly improved the mean power of their upper limbs $(9.08 \%$, $p \leq 0.05)$. Maximal strength did not improve, though, probably due to insufficient training loads. According to Elliott (1978, pp. 2408-2410) depending on the type of physical exercises individual's fitness may improve at the cost of speed and maximal power. In this study, aquatic exercises improved participants' maximal power statistically 
significantly, but the improvement in aerobic threshold was statistically insignificant. This seems to indicate that aqua aerobic exercises can be selected to influence these somatic and physiological characteristics that need strengthening.

It should be noted, however, that in addition to describing the benefits of water exercises the literature provides evidence that physical activity in a swimming pool may have negative effects too. For instance, long and frequent exposure to chlorinated water may lead to the development of upper and lower respiratory symptoms such as asthma (Angione, McClenaghan, LaPlante, 2010; Bernard, Nickmilder, Voisin, 2008; Bougault, Turmel, Levesque, Boulet, 2009).

\section{Conclusions}

After 14 weeks of aqua aerobic workout, the following changes were noted in the participants:

- higher levels of haemoglobin blood concentration, haematocrit, and blood cell count,

- significantly greater fat-free mass and muscle mass and significantly smaller BMI and percentage body fat,

- insignificant differences between lipid profiles recorded at baseline and after intervention,

- significantly higher $\mathrm{WR}_{\max }$ shown by the second ramp test data.

\section{Referenences}

Adamo, M.L., Ferrar, R.P. (2006). Resistance training, and IGF involvement in the maintenance of muscle mass during the aging process. Ageing Res Rev, 3 (5), 310-331.

Adams, K., O'Shea, K.L., O'Shea, P. (1999). Aging: its effects on strength, power, flexibility, and bone density. Strength \& Conditioning Journal, 2 (21), 65-77.

Angione, S., McClenaghan, H., LaPlante, A. (2010). A Review of Chlorine in Indoor Swimming Pools and its Increased Risk of Adverse Health Effects. Interdisciplinary Journal of Health Sciences, 1 (2), $41-47$.

Bellew, J.W. (2002). Older Adults and One - Repetition Maximum Testing: What About Injuries. Journal of Strength and Conditioning Research, 1 (24), 60-62.

Bergamin, M., Ermolao, A., Tolomio, S., Berton, L., Sergi, G., Zaccaria, M. (2013). Water- versus land-based exercise in elderly subjects: effects on physical performance and body composition. Clin Interv Aging, 8, 1109-1117. DOI: 10.2147/CIA.S44198.

Bernard, A., Nickmilder, M., Voisin, C. (2008). Outdoor swimming pools and the risks of asthma and allergies during adolescence. Eur Respir J, 4 (32), 979-988. DOI: 10.1183/09031936.00114807.

Bocalini, D.S., Serra, A.J., Murad, N., Levy, R.F. (2008). Water-based versus land-based exercise effects on physical fitness in older women. Geriatr Gerontol Int, 4 (8), 265-271. DOI: 10.1111/j.1447- 0594.2008.00485.x.

Bougault, V., Turmel, J., Levesque, B., Boulet, L.P. (2009). The respiratory health of swimmers. Sports Med, 4 (39), 295-312. DOI: 10.2165/00007256-200939040-00003.

Broman, G., Quintana, M., Lindberg, T., Jansson, E., Kaijser, L. (2006). High intensity deep water training can improve aerobic power in elderly women. European Journal of Applied Physiology; 2 (98), 117-124.

Carrasco, M., Vaquero, M. (2012). Water training in postmenopausal women: Effect on muscular strength. European Journal of Sport Science, 2 (12), 193-200.

Devereux, K., Robertson, D., Briffa, N.K. (2005). Effects of a water-based program on women 65 years and over: a randomised controlled trial. Aust J Physiother, 2 (51), 102-108.

Elliott, J. (1978). Assessing muscle strength isokinetically. The Journal of the American Medical Association, 22 (240), 2408-2410.

Fernández-Lao, C., Cantarero-Villanueva, I., Ariza-Garcia, A., Courtney, C., Fernández-de-las-Peñas, C., Arroyo-Morales, M. (2013). Water versus land-based multimodal exercise program effects on body composition in breast cancer survivors: a controlled clinical trial. Support Care Cancer, 2 (21), 521-530. DOI: 10.1007/s00520-012-1549-x.

Hagberg, J.M., Graves, J.E., Limacher, M., Woods, D.R., Leggett, S.H., Cononie, C. et al. (1989). Cardiovascular responses of 70- to 79-yr-old men and women to exercise training. J Appl Physiol, 66, 2589-2594. 
Hansen, R.D., Allen, B.J. (2002). Habitual physical activity, anabolic hormones, and potassium content of fat-free mass in postmenopausal women. Am J Clin Nutr, 2 (75), 314-320.

Hirvensalo, M., Rantanen, T., Heikkinen, E. (2000). Mobility difficulties and physical activity as predictors of mortality and loss of independence in the community-living older population. Journal of the American Geriatrics Society, 48, 493-498.

Humphries, B., Triplett-McBride, T., Newton, R.U., Marshall, S., Bronks, R., McBride, J., Häkkinen, K., Kraemeret, W.J. (1999). The relationship between dynamic, isokinetic and isometric strength and bone mineral density in a population of 45 to 65 year old women. J Sci Med Sport, 2 (4), 364-374. DOI: http://dx.doi.org/10.1016/S1440-2440(99)80009-7.

Kamijo, T., Murakami, M. (2009). Regular physical exercise improves physical motor functions and biochemical markers in middle-age and elderly women. Journal of Physical Activity and Health, 6, 55-62.

Kaneda, K., Sato, D., Wakabayashi, H., Hanai, A., Nomura, T.J. (2008). A comparison of the effects of different water exercise programs on balance ability in elderly people. Aging Phys Act, 4 (16), 381-392.

Katsura, Y., Yoshikawa, T., Ueda, S.Y., Usui, T., Sotobayashi, D., Nakao, H., Sakamoto, H., Okumoto, T., Fujimoto, S. (2010). Effects of aquatic exercise training using water-resistance equipment in elderly. European Journal of Applied Physiology, 108, 957-964.

Kim, S.B., O'sullivan, D.M. (2013). Effects of Aqua Aerobic Therapy Exercise for Older Adults on Muscular Strength, Agility and Balance to Prevent Falling during Gait. J Phys Ther Sci, 8 (25), 923-927. DOI: 10.1589/jpts.25.923.

LeMura, L.M., von Duvillard, S.P., Andreacci, J., Klebez, J.M., Chelland, S.A., Russo, J. (2000). Lipid and lipoprotein profiles, cardiovascular fitness, body composition, and diet during and after resistance, aerobic and combination training in young women. Eur J Appl Physiol, 5-6 (82), 451-458.

National Institute on Aging, National Institute of Health (2007). Why Population Aging Matters: A Global Perspective. Retrieved from: http://www.nia.nih.gov, pp. 6-7.

Poyatos, M.C., Abellán, M.V. (2011). Training in a shallow pool: Its effect on upper extremity strength and total body weight in postmenopausal women. International SportMed Journal, 1 (12), 17-30.

Raguso, C.A., Kyle, U., Kossovsky, M.P., Roynette, C., Paoloni-Giacobino, A., Hans, D., Genton, L., Pichard, C. (2006). A 3-year longitudinal study on body composition changes in the elderly: role of physical exercise. Clin Nutr, 4 (25), 573-580.

Rotstein, A., Harush, M., Vaisman, N. (2008). The effect of a water exercise program on bone density of postmenopausal women. $J$ Sports Med Phys Fitness, 3 (48), 352-359.

Roubenoff, R. (2007). Physical activity, inflammation, and muscle loss. Nutr. Rev, 65, 208-212.

Ruoti, R.G., Troup, J.T., Berger, R.A. (1994). The effects of nonswimming water exercises on older adults. J Orthop Sports Phys Ther, $3(19), 140-145$

Sato, D., Kaneda, K., Wakabayashi, H., Shimoyama, Y., Baba, Y., Nomura, T. (2011). Comparison of once and twice weekly water exercise on various bodily functions in community-dwelling frail elderly requiring nursing care. Arch Gerontol Geriatr, 3 (52), 331-335. DOI: 10.1016/j.archger.2010.05.002.

Sheldahl, L.M., Buskirk, E.R., Loomis, J.L., Hodgson, J.L., Mendez, J. (1982). Effects of exercise in cool water on body weight loss. Int J Obes, 1 (6), 29-42.

Simmons, V., Hansen, P.D. (1996). Effectiveness of water exercise on postural mobility in the well elderly: an experimental study on balance enhancement. J Gerontol A Biol Sci Med Sci, 5 (51), 233-238.

Sonati, J.G., Modeneze, D.M., Vilarta, R., Maciel, E.S,. Boccaletto, E.M. (2011). Body weight as an indicator of fat-free mass in active elderly women. Maturitas, 4 (68), 378-381.

Speakman, J.R., Westerterp, K.R. (2010). Associations between energy demands, physical activity, and body composition in adult humans between 18 and 96 y of age. Am J Clin Nutr, 4 (92), 826-834.

Struck, B.D., Ross, K.M. (2006). Health promotion in older adults. Prescribing exercise for the frail and home bound. Geriatrics, 61 , 22-27.

Takeshima, N., Rogers, M.E. Watanabe, E., Brechue, W.F., Okada, A., et al. (2002). Water-based exercise improves health-related aspects of fitness in older women. Medicine and Science in Sports and Exercise, 3 (34), 544-552.

Taunton, J.E., Rhodes, E.C., Wolski, L.A., Donelly, M., Warren, J., Elliot, J., McFarlane, L., Leslie, J,. Mitchell, J., Lauridsen, B. (1996). Effect of land-based and water-based fitness programs on the cardiovascular fitness, strength and flexibility of women aged 65-75 years. Gerontology, 4 (42), 204-210.

Torlaković, A., Radjo, I., Dautbašić, S., Gec, M. (2010). Effects of combined programmes swimming, aqua aerobic and aerobic for elderly people. 6th International Conference "Movement and Health" and 2nd HEPA Europe Conference. Acta Universitatis Gymnica, 3 (40), 111. 
Tsourlou, T., Benik, A., Zafeiridis, A., Kellis, S. (2006). The effects of a twenty-four week aquatic training program on muscular strength performance in healthy elderly women. Journal of Strength and Conditioning Research, 4 (20), 811-819.

United Nations, Department of Economic and Social Affairs, Population Division (2013). World population prospects: The 2012 Revision. Highlights and advance tables. Retrieved from: http:/lesa.un.org.

Cite this anticle aS: Kantyka, J., Herman, D, Roczniok, R. (2017). Effect of Aqua Aerobics on Selected Somatic, Physiological and Aerobic Capacity Parameters in Postmenopausal Women. Central European Journal of Sport Sciences and Medicine, 4 (20), 13-22. DOI: 10.18276/cej.2017.4-02. 